удК 622.279 .72

\title{
СОВЕРШЕНСТВОВАНИЕ ПРОЦЕССА СОЛЯНОКИСЛОТНОЙ ОБРАБОТКИ СКВАЖИН ПРИМЕНЕНИЕМ НОВЕЙШИХ ТЕХНОЛОГИЙ И ОБОРУДОВАНИЯ
}

\author{
Хабибуллин Марат Яхиевич, \\ m-hab@mail.ru \\ Филиал Уфимского государственного нефртяного технического университета в г. Октябрьский, \\ Россия, 452607, г. Октябрьский, ул. Девонская, 54-а.
}

\begin{abstract}
Актуальность исследования обусловлена необходимостью обеспечивать равномерный нагрев раствора кислоты при скоростях закачки, создаваемых агрегатами, на термокислотные образцы. Решение этой проблемы позволит повысить эфффективность кислотных и термокислотных обработок сильно дренированных скважин с низким пластовым давлением.

Цель: разработать и предложить метод кислотного и термокислотного импульсирования, методику его применения и создать конструкции подземного и наземного оборудования скважин для осуществления разработанного метода.

Объекты. Объем раствора, заливаемого в насосно-компрессорные трубы при термокислотной обработке методом импульсирования, зависит от их длины и внутреннего диаметра. Обычно он принимается равным 1,2-2 м³. Если в скважине, намеченной для проведения термокислотной обработки методом импульсирования, фильтр или его некоторая часть оказывались перекрытыми песчаной пробкой, то их предварительно очищали желонкой, не вскрывая зумпфа. А также используется специальный перфорированный наконечник и специальная заливочная головка.

Методы. Термокислотную (как и кислотную) обработку скважины методом импульсирования проводят без применения насосного агрегата, что позволяет значительно сократить расходы. Ускорение движения кислотного раствора, нагрев всего объема до нужной температуры и создание давления (за счет веса столба раствора) способствуют увеличению глубины проникновения и эфрфективности воздействия кислоты на пласт.

Результаты. Наиболее подходящим кислотным раствором для термокислотного импульсирования является 15\%-я $\mathrm{HCl}$, ингибированная униколом. Хорошие результаты дало внедрение способа кислотного импульсирования, предусматривающего использование специального наконечника, в котором канал штуцера полностью закрыт магниевым стержнем. В результате реакции магниевый стержень растворяется в кислотном растворе, после чего последний устремляется через освободившийся канал штуцера и перфорированньй патрубок в фильтр, создавая так называемый кислотный импульс, m. е. достиеается повышение скорости закачки под действием гидростатического давления.
\end{abstract}

Ключевые слова:

Скорость, закачка, реактор, уникол, магний, стружка, песчаный.

\section{Введение}

Скорость закачки неравномерного нагрева кислоты при термокислотных образцах, создаваемая агрегатами, обусловлена следующим. Первая порция раствора перегревается, а последующие оказываются недостаточно нагретыми. Поэтому эффективность кислотных и термокислотных обработок сильно дренированных скважин с низким пластовым давлением довольно низкая [1-4]. Для повышения эффективности предложен метод кислотного и термокислотного импульсирования, разработана методика его применения и созданы несложные конструкции необходимого подземного и наземного оборудования скважин (реакторынаконечники и универсальная устьевая головка).

Способ термокислотного импульсирования основан на применении специального реакторанаконечника (рис. 1). Реактор, основными узлами которого являются клапан и собственно реактор, заполненный магниевой стружкой, спускают в скважину на насосно-компрессорных трубах до упора в забой своим перфорированным патрубкомнаконечником. В момент упора шток корпуса клапана поднимает шарик с седла клапана, и кислотный раствор, предварительно залитый в насоснокомпрессорные трубы, проникает в прифильтровую зону продуктивного пласта. Скорость прохождения раствора из колонны насосных труб через реактор с магниевой стружкой вначале гораздо выше скорости, которая создавалась при закачке кислотного раствора агрегатом. Затем по мере снижения уровня кислотного раствора в трубах скорость вытекания его уменьшается. Таким образом, достигается равномерный прогрев кислотного раствора до требуемой примерно постоянной температуры [5-8].

Следует отметить, что в скважинах до термокислотной обработки методом импульсирования безуспешно проводились обычные кислотные и термокислотные обработки. Скорость истечения кислотного раствора из насосно-компрессорных труб после открытия клапана реактора-наконечника при проведении термокислотного импульсирования показана на рис. 2.

Объем раствора, заливаемого в насоснокомпрессорные трубы при термокислотной обработке методом импульсирования, зависит от их длины и внутреннего диаметра. Обычно он принимается равным 1,2-2 $\mathrm{m}^{3}$.

Если в скважине, намеченной для проведения термокислотной обработки методом импульсирования, фильтр или его некоторая часть оказывались перекрытыми песчаной пробкой, то их предварительно очищали желонкой, не вскрывая зумпфа [9-11].

Термокислотную (как и кислотную) обработку скважины методом импульсирования проводят без применения насосного агрегата, что позволяет значительно сократить расходы. 

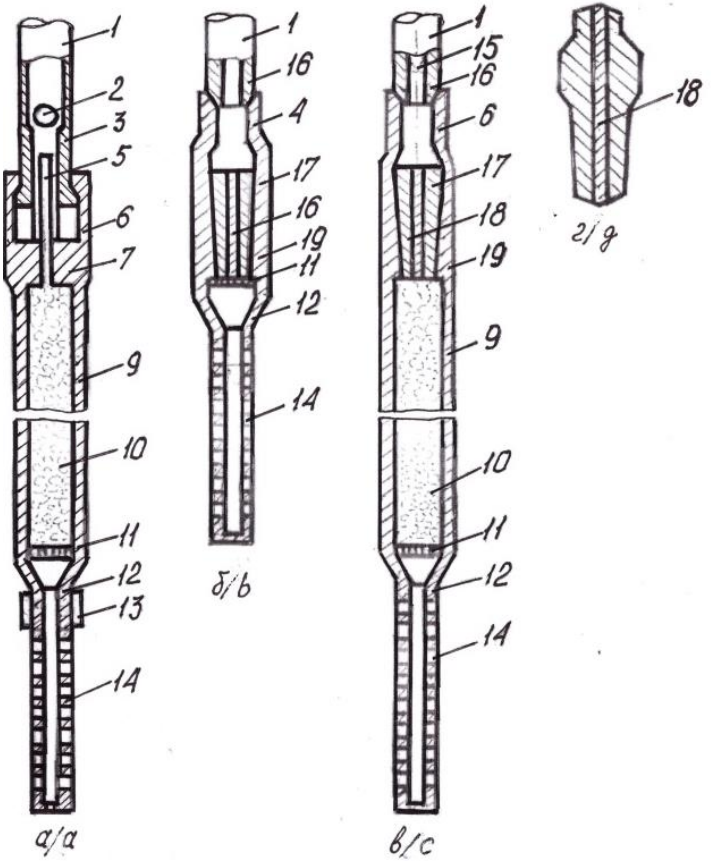

Рис. 1. Реакторы-наконечники для кислотной и термокислотной обработки скважин методом импульсирования: а) реактор-наконечник для термокислотного импульсирования; б) наконечник для кислотного импульсирования; в) универсальный реактор-наконечник для кислотного и термокислотного импульсирования; г) конус с магниевым стержнем (сбрасываемый в скважину при многократной обработке). 1 - насосно-компрсссорная труба; 2 - шарик клапана; 3 - седло клапана; 4 муфта переводная; 5 - соединительный патрубок, 6 - упорный патрубок; 7 - корпус клапана; 9 - реактор; 10 - магниевая стружка; 11 - фильтр (решетка); 12 - переводник; 13 - муфта содинительная; 14 - перфорированный патрубокнаконечник; 15 - седло для конуса с магниевым стержнем; 16 - соединительный патрубок (переводник); 17 - вкладыи итуиера: 18 - магниевый стержень; 19 - корпус штуиера

Fig. 1. Reactor-tips for acid and thermo-acid treatment of wells by the method of impulse: a) reactor-tip for thermo-acid impulse; b) tip for acid impulse; c) universal reactor-tip for acid and thermo-acid impulses; g) cone with a magnesium rod (discharged into the well during repeated processing). 1 - pumpcompressor pipe; 2 -valve ball; 3 -valve seat; 4 coupling transferable; 5 - connecting pipe; 6 - persistent branch pipe; 7 - valve body; 9 - reactor; 10 - magnesium shavings; 11 - filter (grill); $12-$ sub; 13 - coupling conjoint; 14 - perforated nozzletip; 15 - saddle for a cone with a magnesium core; 16 - connecting pipe (sub); 17 - fitting insert; 18 magnesium rod; 19 - fitting body

Ускорение движения кислотного раствора, нагрев всего объема до нужной температуры и создание давления (за счет веса столба раствора) способствуют увеличению глубины проникновения и эффективности воздействия кислоты на пласт.

На рис. 3 показаны термограммы, снятые при импульсной прокачке кислоты (с переменным напором) через стружку магния.

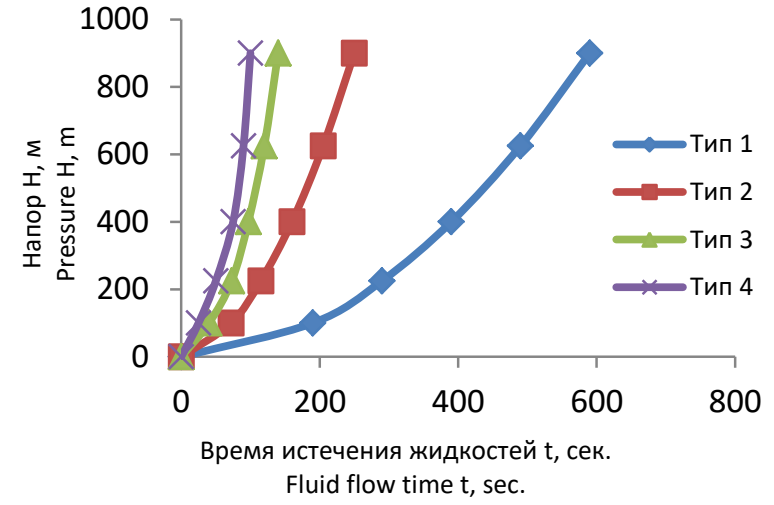

Pис. 2. Расчетное время $t$ истечения жидкости из 73-мм труб при переменном напоре $Н$ в зависимости от диаметра штуиера $d$ : Tun 1: $d=10$ мм, Tuп 2: $d=15$ мM, Tun 3: $d=20$ мM, Tun 4: $d=25$ мM

Fig. 2. Estimated time $t$ of fluid outflow from $73 \mathrm{~mm}$ pipes with a variable head $H$ depending on the diameter of the nozzle d: Type 1: $d=10 \mathrm{~mm}$, Type 2: $d=15 \mathrm{~mm}$, Type 3: $d=20 \mathrm{~mm}$, Type 4: $d=25 \mathrm{~mm}$

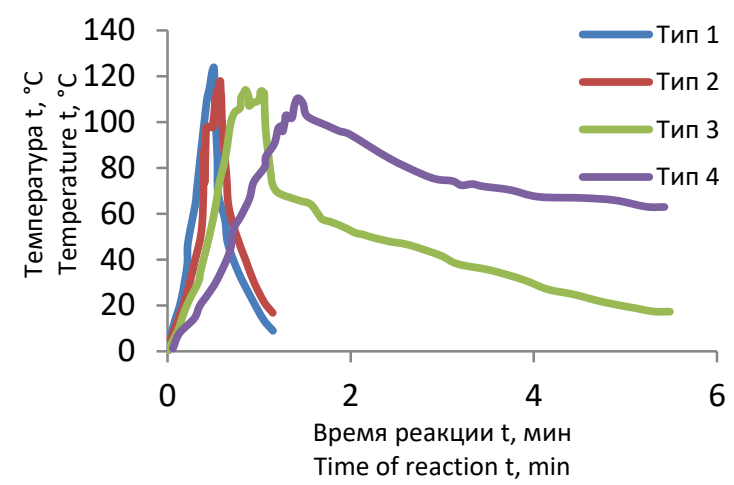

Рис. 3. Термограммы, снятые на стендовой установке в прочессе термокислотного импульсирования при реакиии: Тип 1 - 10\%-й НСI со стружкой магния Tun 2 - 15\%-й НCI со стружкой магния; Tun 3 15\%-й HC1, ингибированной формалином; Tип 4 15\%-й НC1, ингибированной униколом

Fig. 3. Thermograms taken on a bench installation in the process of thermo-acid impulse during the reaction: Type 1-10\% HCI with magnesium chips; Type 2$15 \%$ HCI with magnesium chips; Type $3-15 \%$ $\mathrm{HCl}$ inhibited by formalin; Type $4-15 \% \mathrm{HCl}$ inhibited by unicol

Соляная кислота $15 \%$-й концентрации препарировалась формалином и униколом. Известно, что время реакции солям кислоты с магнием зависит от присутствия в кислотном растворе этих ингибиторов. Применение уникола для ингибирования кислоты, которая идет на термохимическую часть процесса, тормозит реакцию, особенно при повышенном давлении, почти в 20 раз [12, 13].

После каждой опытной прокачки соляной кислоты фиксировалась остаточная кислотность раствора (табл. 1).

Вначале способ термокислотного импульсирования предназначался для сильно дренированных скважин. Но, как показала практика, его можно успешно применять и при обработке скважин других катего- 
рий, причем в зависимости от диаметра эксплуатационной колонны и диаметра реактора (кожуха) расход кислоты может быть изменен. Обычно применяется 114-мм реактор, но для 114- или 127-мм эксплуатационной колонны можно использовать реактор диаметром 48 или 88 мм, соответственно удлиненный для сохранения необходимой емкости, чтобы уместить нужное количество магниевой стружки.

Таблица 1. Остаточная кислотность раствора после термокислотного импульсирования

Table 1. Residual acidity of the solution after thermoacid pulsation

\begin{tabular}{|c|c|}
\hline $\begin{array}{c}\text { Кислотный рас-р после реакции } \\
\text { с магнием, \% } \\
\text { Acid solution after reaction } \\
\text { with magnesium, \% }\end{array}$ & $\begin{array}{c}\text { Остаточное } \\
\text { содержание } \\
\text { HCl } \\
\text { Residual HCl } \\
\end{array}$ \\
\hline $10 \%$-я $\mathrm{HCl}$ & 9,5 \\
\hline $15 \%$-я $\mathrm{HCl}$ & 13,7 \\
\hline $15 \%$-я HCl, ингибированная формалином & \\
\hline $15 \%$ formalin inhibited $\mathrm{HCl}$ & 12,9 \\
\hline $15 \%$ ая $\mathrm{HCl}$, ингибированная униколом & \\
\hline $15 \%$ unicol inhibited $\mathrm{HCl}$ & 12,4 \\
\hline
\end{tabular}

Наконечник (рис. $1, a$ ), несмотря на простоту своей конструкции, все же имел существенный недостаток: раскрытие клапана было сопряжено с допуском хвостовика до забоя. В условиях пескопроявлений, когда в процессе эксплуатации скважин песок скапливается на забое, спуск хвостовика до упора в забой связан с опасностью прихвата труб. Поэтому был предложен и внедрен новый специальный наконечник [14-16]. Основная часть этого наконечника представляет собой штуцер, канал которого закрыт магниевым стержнем (рис. 1, в).

Хорошие результаты дало внедрение способа кислотного импульсирования, предусматривающего использование специального наконечника, в котором канал штуцера полностью закрыт магниевым стержнем (рис. 1, б) [17]. Наконечник спускают в скважину на насосно-компрессорных трубах до тех пор, пока перфорированный патрубок его не установится против эксплуатационного объекта (в этом случае не нужно, чтобы патрубок упирался в забой). Затем в колонну насосно-компрессорных труб заливают кислотный раствор, который удерживается в ней вследствие перекрытия канала штуцера магниевым стержнем.

В результате реакции магниевый стержень растворяется в кислотном растворе, после чего последний устремляется через освободившийся канал штуцера и перфорированный патрубок в фильтр, создавая так называемый кислотный импульс, т. е. достигается повышение скорости закачки под действием гидростатического давления. Давление, создающееся при этом на забое сильно дренированной скважины, способствует значительно большему проникновению активного кислотного раствора в пласт по сравнению с обычной кислотной обработкой.

Длину магниевого стержня подбирают по составленной нами номограмме (рис. 2), в основу которой были положены лабораторные исследования растворения магниевого стержня длиной 10 мм и диаметром 10 мм (помещенного в патрон наподобие вкладыша) в 15\%-м растворе соляной кислоты [18]. При построении номограммы исходили из расчета, что полное растворение магниевого стержня должно наступить не раньше полной заливки труб кислотным раствором (в момент окончания последней).

Задаваясь длиной и диаметром спускаемых в скважину насосно-компрессорных труб, определяют объем кислотного раствора. Далее, задаваясь скоростью слива кислотного раствора в насоснокомпрессорные трубы (регулируемой открытием вентиля на автоцистерне), находят время заливки труб и длину магниевого стержня. Так, в указанном случае при скорости слива 1 л/сек время заливки равно 53 мин, а длина стержня - 17 мм.

Существенным недостатком способа кислотного импульсирования (как и термокислотного) является ограничение объема кислотного раствора емкостью спущенных насосно-компрессорных труб.

Следует заметить, что часто бывает целесообразно использовать больший объем раствора. Поэтому был предложен и внедрен способ многократного кислотного импульсирования без извлечения насоснокомпрессорных труб из скважин. Для применения указанного способа предложен универсальный реактор-наконечник (рис. 1, в, г).

Проведение многократного импульсирования стало возможным потому, что в комплекте нового реактора имеется ряд конусных седел, устанавливаемых последовательно в насосно-компрессорных трубах (на рис. 1, в показано лишь одно седло - 15); причем диаметр отверстия в каждом седле, расположенном выше, больше, чем у седла, находящегося ниже. После проведения однократного кислотного импульсирования в насосно-компрессорные трубы забрасывается конус (рис. 1, г), который перекрывает отверстие седла. Отверстие конуса заполнено магниевым стержнем - 18. Затем можно снова заливать кислотный раствор в насосно-компрессорные трубы и т. д. (как при однократном кислотном импульсировании). Эту операцию можно повторять несколько раз, используя заранее установленные седла и забрасывая каждый раз соответствующие конусы с магниевыми стержнями (длина их во всех случаях определяется по номограмме) [19]. При многократном импульсировании число импульсов определяют исходя из выбранного объема кислотного раствора и объема раствора, который можно поместить в спущенные трубы.

В сильно дренированных скважинах целесообразно сначала провести термокислотное импульсирование (особенно если из нее добывалась парафинистая нефть). Для этого можно использовать универсальный реактор-наконечник (рис. 1, в). После термокислотного импульсирования можно, не поднимая труб, проводить нужное число раз кислотное импульсирование. Для этого надо предварительно установить в насосно-компрессорных трубах необходимое число седел - 15 (рис. 1, в) и забрасывать перед каждой кислотной импульсной обработкой соответствующий конус с магниевым стержнем (рис. 1, 2).

При использовании обычной заливочной головки поршнеобразное движение раствора в трубах вызыва- 
ло периодические прорывы воздуха к устью скважины. При этом воздух увлекал за собой и кислотный раствор, поэтому приходилось периодически прекращать заливку раствора в трубы.

Предложена специальная заливочная головка (рис. 4). Внешний 73-мм патрубок - 2 головки имеет отвод - 3 для слива кислотного раствора в насоснокомпрессорные трубы - 6, а внутренний 48-мм патрубок - 1 служит для выхода вытесняемого в атмосферу воздуха. После того как спущены трубы и на них установлена указанная головка, через отвод - 3 сливается кислотный раствор. Попадая в кольцевое пространство, раствор вначале стекает по направляющим - 8, а затем по стенкам насосно-компрессорных труб - 6. Вытесняемый воздух занимает центральное положение и удаляется через патрубок - 1. В результате внедрения такой головки исключены потери времени на слив в трубы кислотного раствора, а также потери последнего из-за выбросов (вместе с воздухом); загрязнения устья скважины, а также обеспечивается безопасность труда работников, занятых импульсной кислотной обработкой.

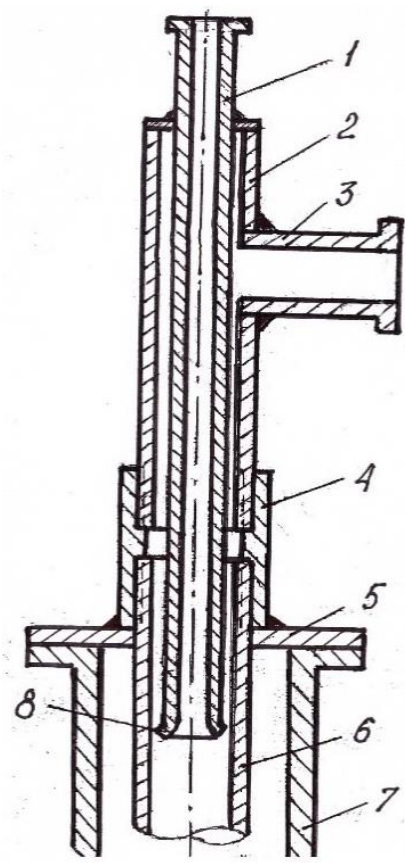

Pис. 4. Универсальная устьевая головка для кислотной и термокислотной обработки скважин методом импульсирования: 1 - 48-мм патрубок; 2 - 73-мм патрубок; 3 - 73-мм отвод; 4 - посадочная муфта; 5 - планшайба; 6 - насоснокомпрессорная труба; 7 - эксплуатационная колонна; 8 - направляюшие для стока кислотного раствора

Fig. 4. Universal wellhead for acid and thermal acid treatment of wells by a pulsation method: $1-48 \mathrm{~mm}$ nozzle; 2 - $73 \mathrm{~mm}$ pipe; 3 - $73 \mathrm{~mm}$ bend; 4 -landing clutch; 5 -faceplate; 6 -tubing; 7 -production casing; 8 - guides for drainage of acid solution

В целях установления эффективности импульсных термокислотных обработок по сравнению с операциями простых термокислотных работ определена вероятность удачных операций. При этом асимметричное распределение скважин по эффективности было выровнено при помощи распределения Шарлье [20].

Результаты вычисления вероятности удачных исходов при импульсных термокислотных обработках приведены в табл. 2, где также для сопоставления указана и вероятность эффективности обычных термокислотных обработок, подсчитанных выше.

Таблица 2. Вероятность эффективности операций

Table 2. Probability of operational efficiency

\begin{tabular}{|c|c|c|c|c|}
\hline \multirow[b]{3}{*}{$\begin{array}{l}\text { Операции } \\
\text { Operations }\end{array}$} & \multicolumn{4}{|c|}{$\begin{array}{c}\text { По результатам вычислений } \\
\text { According to the results of calculation }\end{array}$} \\
\hline & \multicolumn{2}{|c|}{$\begin{array}{c}\text { прироста } \\
\text { дебита } \\
\text { growth rate }\end{array}$} & \multicolumn{2}{|c|}{$\begin{array}{c}\text { продолжительности } \\
\text { работы скважины } \\
\text { на повышенном дебите } \\
\text { duration of well operation } \\
\text { at increased flow rate }\end{array}$} \\
\hline & 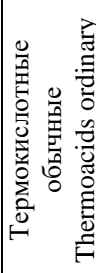 & 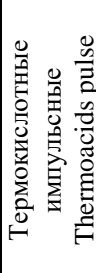 & 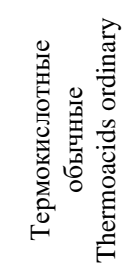 & 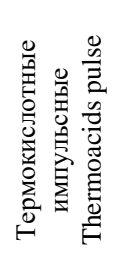 \\
\hline $\begin{array}{l}\text { Высокоэффективные } \\
\text { Highly efficient }\end{array}$ & 9 & 22 & 7 & 11 \\
\hline $\begin{array}{l}\text { Эффективные } \\
\text { Efficient }\end{array}$ & 11 & 34 & 22 & 23 \\
\hline $\begin{array}{l}\text { Неэффективные } \\
\text { Inefficient }\end{array}$ & 80 & 44 & 73 & 66 \\
\hline
\end{tabular}

Следует отметить, что сопоставление двух групп чисел может быть справедливым при условии, когда отличие их средних незначительно. Указанные группы чисел были обработаны, в результате чего установлено, что совокупность, представленная ими, различна. Как видно из табл. 2, эффективность операций по кислотным обработкам путем импульсирования больше эффективности термокислотных обработок по результатам вычислений как прироста дебита нефти, так и продолжительности работы скважин на повышенном дебите.

\section{Заключение}

На основании проведенных опытов можно сделать следующие выводы.

1) Процесс термокислотного импульсирования для достижения равномерного нагрева кислотного раствора регулируется путем:

a) повышения давления прокачки (напор регулируется столбом жидкости, заливаемой в трубы);

б) уменьшения скорости закачки; скорость прохождения раствора из колонны насосных труб через реактор с магниевой стружкой вначале оказывается гораздо выше скорости, создаваемой при закачке кислотного раствора агрегатом; затем по мере падения уровня кислоты в трубах скорость истечения ее снижается; в результате достигается равномерный прогрев кислотного раствора до требуемой температуры.

2) Ингибирование $\mathrm{HCl}$ формалином и униколом тормозит реакцию. Однако только уникол спосо- 
бен растянуть реагирование НCI с магнием на необходимое время, в течение которого протекает весь процесс прокачки кислоты через сопла.

Таким образом, наиболее подходящим кислотным раствором для термокислотного импульсирования является $15 \%$-я $\mathrm{HCl}$, ингибированная униколом.

В результате реакции магниевый стержень растворяется в кислотном растворе, после чего последний устремляется через освободившийся канал штуцера и перфорированный патрубок в фильтр, создавая так называемый кислотный импульс, т. е. достигается повышение скорости закачки под действием гидростатического давления. Давление, создающееся при этом на забое сильно дренированной скважины, спо-

\section{СПИСОК ЛИТЕРАТУРЬ}

1. Кислотная обработка призабойной зоны пласта баженовской свиты после проведения гидроразрыва пласта / В.Т. Литвин, К.В. Стрижнев, Т.Н. Шевчук, П.В. Рощин // Нефтяное хозяйство. - 2018. - № 4. - С. 70-73.

2. Khabibullin M.Ya. Development of the design of the sucker-rod pump for sandy wells // IOP Conference Series: Materials Science and Engineering. - 2019. - P. 012065. DOI: 10.1088/1757899X/560/1/012065.

3. Zhang H., Liang Y., Zhou X. Sensitivity analysis and optima operation control for large-scale water flooding pipeline network of oilfield // Journal of petroleum science and engineering. 2017. - V. 154. - P. 38-48.

4. Khabibullin M.Ya., Suleimanov R.I. Selection of optimal design of a universal device for nonstationary pulse pumping of liquid in a reservoir pressure maintenance system // Chemical and Petroleum Engineering. - 2018. - V. 54. - Iss. 3-4. - P. 225-232. DOI: $10.1007 / \mathrm{s} 10556-018-0467-2$

5. Эффективность кислотных обработок нагнетательных скважин / К.Ш. Ямалетдинова, А.Ш. Халадов, Ю.В. Дудников, А.А. Ямалетдинова, А.Р. Габдуллин // Успехи современного естествознания. - 2017. - № 12. - C. 278-283; URL http://www.natural-sciences.ru/ru/article/view?id=36642 (дата обращения: 24.01.2020).

6. Meirmanov A., Nekrasova I. Mathematical models of a hydraulic shock // Journal of mathematical analysis and applications. 2013. - V. 408. - Iss. 1. - P. 76-90.

7. Studying heat-affected zone deformations of electric arc welding / R.I. Suleimanov, L.Z. Zainagalina, M.Y. Khabibullin, L.M. Zaripova, N.O. Kovalev // IOP Conference Series:Materials Science and Engineering. - 2018. - P. 032053. DOI: 10.1088/1757-899X/327/3/032053

8. Кислотные обработки: составы, механизмы реакций, дизайн / В.Н. Глущенко, О.А. Пташко, Р.Я. Харисов, А.В. Денисова. Уфа: Гилем, 2010. - 392 с

9. Kadochnikova L.M., Pichugin O.N., Chebakov A.A. Analytical technique for gel treatment prediction of production and injection wells in a stratified reservoir // Iranian Journal of Science \& Technology. - 2002. - Transaction B. - V. 26. - B2. - P. 205-216.

10. Zaichenko A.Yu., Glazov S.V., Salgansky E.A. Filtration combustion of viscous hydrocarbon liquids // Theoretical foundations of chemical engineering. - 2017. - V. 51. - Iss. 5. P. 673-679.

11. The application of X-ray Micro Computed Tomography (MicroCT) of core sample for estimation of physicochemical treatment efficiency / M.S. Orlov, P.V. Roschin, I.A. Struchkov, V.T. Litvin // собствует значительно большему проникновению активного кислотного раствора в пласт по сравнению с обычной кислотной обработкой.

Конструкция этого устройства имеет следующие преимущества:

1) штуцер открывается без применения трактораподъемника;

2) процесс кислотной обработки можно проводить в скважинах, имеющих зумпф (карман ниже фильтровой зоны) значительной длины;

3) при наличии песчаной пробки или построении предметов на забое отсутствует опасность прихвата труб.

SPE Russian Petroleum Technology Conference. - Moscow, Russia, 2015. SPE-176600-MS. DOI: 10.2118/176600-MS

12. Коннов Ю.Д. Сидоркин Д.И., Хабибуллин М.Я. Механизация технологического процесса спуско-подъемных операций при текущем и капитальном ремонте скважин // Научные труды НИПИ Нефтегаз ГНКАР. - 2018. - № 2. - C. 15-24. DOI: 10.5510/OGP20180200346.

13. Assem A.I., Nasr-El-Din H.A., De Wolf C.A. Formation damage due to iron precipitation in carbonate rocks // SPE European Formation Damage Conference \& Exhibition. - 2013. URL: http:// dx.doi.org/10.2118/165203-MS (дата обращения: 24.01.2020).

14. Wenyue S., Mun-Hong H. Forecasting and uncertainty quantification for naturally fractured reservoirs using a new dataspace inversion procedure // 15th Conference on the Mathematics of Oil Recovery (ECMOR). - Amsterdam, Netherlands: European Assoc. Geoscientists \& Engineers Computational geosciences, 2017. - V. 21. - Iss. 5-6. - P.1443-1458.

15. Rady A. Iron precipitation in calcite, dolomite and sandstone cores // SPE Russian Petroleum Technology Conference. - 2015. URL: http://dx.doi.org/10.2118/176574-MS (дата обрашения: 24.01.2020).

16. Rabie A.I. Sodium gluconate as a new environmentally friendly iron-controlling agent for HP/HT acidizing treatments // SPE Middle East Oil \& Gas Show and Conference. - 2015. URL: http://dx.doi.org/10.2118/172640-MS (дата обращения: 24.01.2020).

17. Литвин В.Т., Стрижнев К.В., Рощин П.В. Особенности строения и интенсификации притоков нефти в сложных коллектоpax баженовской свиты Пальяновского месторождения // Нефтегазовая геология. Теория и практика. - 2015. - Т. 10. № 3. URL: http://www.ngtp.ru/rub/11/36_2015.pdf (дата обращения: 24.01.2020)

18. Гилаев Ген.Г., Хабибуллин М.Я., Гилаев Г.Г. Перспективы применения кислотного геля для закачки проппанта в процессе проведения гидроразрыва карбонатных пластов на территории самарской области // Нефтяное хозяйство. - 2020. № 8. - C. 54-57.

19. Nsoga V.N., Hona J., Pemha E. Numerical simulation of heat distribution with temperature-dependent thermal conductivity in a two-dimensional liquid flow // International Journal of nonlinear sciences and numerical simulation. - 2017. - V. 18. - Iss. 6. P. 507-513.

20. Abdyukova R.Y. Studies on operation and types of drilling pump valves // IOP Conference Series: Materials Science and Engineering. - 2019. - P. 012050. DOI: 10.1088/1757$899 \mathrm{X} / 560 / 1 / 012050$

Поступила 23.09.2020 г.

\section{Информация об авторах}

Хабибуллин М.Я., кандидат технических наук, доцент кафедры нефтепромысловых машин и оборудования, филиал Уфимского государственного нефтяного технического университета в г. Октябрьский. 
UDC 622.279 .72

\title{
IMPROVEMENT OF HYDROXYLIC ACID WELL PROCESSING APPLYING THE LATEST TECHNOLOGIES AND EQUIPMENT
}

\author{
Marat Ya. Khabibullin, \\ m-hab@mail.ru \\ Branch of the Ufa State Petroleum Technical University in Oktyabrsky, \\ 54-a, Devonskaya avenue, Oktyabrsky, 452607, Russia.
}

The relevance the research is caused by the need to ensure uniform heating of the acid solution at the injection rates created by the units onto the thermoacid samples. A solution to this problem will improve the efficiency of acid and thermal acid treatments of highly drained wells with low reservoir pressure.

The main aim of the research is to develop and propose a method of acid and thermoacid impulse, a methodology for its application and to create structures for underground and surface equipment of wells for implementation of the developed method.

Objects. The volume of the solution poured into the tubing during thermo-acid treatment by the pulsing method depends on their length and inner diameter. Usually it is taken equal to 1,2-2 $\mathrm{m}^{3}$. If the filter or some its part turned out to be blocked with a sand plug in the well, scheduled for thermal acid treatment by the pulsing method, then they were preliminarily cleaned with a thief without opening the sump. $A$ special perforated tip and a special filling head are used as well.

Methods. Thermal acid (as well as acidic) treatment of a well by the pulsing method is carried out without the use of a pump unit, which can significantly reduce costs. Accelerating the movement of the acid solution, heating the entire volume to the desired temperature and creating pressure (due to the weight of the solution column) contribute to an increase in the depth of penetration and the effectiveness of the action of the acid on the formation.

Results. The most suitable acid solution for thermoacid impulse is $15 \% \mathrm{HCl}$, inhibited by unicol. Good results were obtained by introduction of the acid impulse method, which involves the use of a special tip, in which the nozzle channel is completely closed with a magnesium rod. As a result of the reaction, the magnesium rod dissolves in the acid solution, after which the latter rushes through the vacated choke channel and the perforated pipe into the filter, creating the so-called acid pulse, i. e. increase in the injection rate is achieved under the action of hydrostatic pressure.

Key words:

Speed, injection, reactor, unicol, magnesium, shavings, sand.

\section{REFERENCE}

1. Litvin V.T., Strizhnev K.V., Shevchuk T.N., Roshchin P.V. Acid treatment bottomhole formation zone of the Bazhenov formation after hydraulic fracturinglayer. Oil industry, 2018, no. 4, pp. 70-73. In Rus.

2. Khabibullin M.Ya. Development of the design of the sucker-rod pump for sandy wells. IOP Conference Series: Materials Science and Engineering, 2019, pp. 012065. DOI: 10.1088 / 1757-899X / $560 / 1 / 012065$

3. Zhang H., Liang Y., Zhou X. Sensitivity analysis and optimal operation control for large-scale waterflooding pipeline network of oilfield. Journal of petroleum science and engineering, 2017, vol. 154 , pp. 38-48.

4. Khabibullin M.Ya., Suleimanov R.I. Selection of optimal design of a universal device for nonstationary pulse pumping of liquid in a reservoir pressure maintenance system. Chemical and Petroleum Engineering, 2018, vol. 54, Iss. 3-4, pp. 225-232. DOI: $10.1007 / \mathrm{s} 10556-018-0467-2$

5. Yamaletdinova K.Sh., Khaladov A.Sh., Dudnikov Yu.V., Yamaletdinova A.A., Gabdullin A.R. The effectiveness of acid treatments for injection wells. Successes modern science, 2017, no. 12 pp. 278-283; URL: http://www.natural-sciences.ru/ru/article/ view?id=36642 (accessed: 01.24.2020). In Rus.

6. Meirmanov A., Nekrasova I. Mathematical models of a hydraulic shock. Journal of mathematical analysis and applications, 2013, vol. 408, Iss. 1, pp. 76-90.

7. Suleimanov R.I., Zainagalina L.Z., Khabibullin M.Y., Zaripova L.M., Kovalev N.O. Studying heat-affected zone deformations of electric arc welding. IOP Conference Series:Materials Science and Engineering, 2018, p. 032053. DOI: 10.1088/1757899X/327/3/032053.

8. Glushchenko V.N., Ptashko O.A., Kharisov R.Ya., Denisova A.V. Acid treatments: compositions, reaction mechanisms, design. Ufa Guillem, 2010. 392 p.

9. Kadochnikova L.M., Pichugin O.N., Chebakov A.A. Analytical technique for gel treatment prediction of production and injection wells in a stratified reservoir. Iranian Journal of Science \& Technology, 2002, Transaction B, vol. 26, B2, pp. 205-216.

10. Zaichenko A.Yu., Glazov S.V., Salgansky E.A. Filtration combustion of viscous hydrocarbon liquids. Theoretical foundations of chemical engineering, 2017, vol. 51, Iss. 5, pp. 673-679.

11. Orlov M.S., Roschin P.V., Struchkov I.A., Litvin V.T. The application of X-ray Micro Computed Tomography (Micro-CT) of core sample for estimation of physicochemical treatment efficiency. SPE Russian Petroleum Technology Conference. Moscow, Russia, 2015. SPE-176600-MS. DOI: 10.2118/176600-MS

12. Konnov Yu.D., Sidorkin D.I., Khabibullin M.Ya. Mechanization of the technological process of tripping and lifting operations during routine and overhaul of wells. Scientific works of NIPI Neftegaz SOCAR, 2018, no. 2, pp. 15-24. DOI: 10.5510/OGP20180200346. In Rus.

13. Assem A.I., Nasr-El-Din H.A., De Wolf C.A. Formation damage due to iron precipitation in carbonate rocks. SPE European Formation Damage Conference \& Exhibition, 2013. Available at: http://dx.doi.org/10.2118/165203-MS (accessed: 24 January 2020).

14. Wenyue S., Mun-Hong H. Forecasting and uncertainty quantification for naturally fractured reservoirs using a new data-space inversion procedure. $15^{\text {th }}$ Conference on the Mathematics of Oil Recovery (ECMOR). Amsterdam, Netherlands, European Assoc. Geoscientists \& Engineers Computational geosciences, 2017. Vol. 21 , Iss. 5-6, pp. 1443-1458.

15. Rady A. Iron precipitation in calcite, dolomite and sandstone cores. SPE Russian Petroleum Technology Conference. 2015. Available at: http://dx.doi.org/10.2118/176574-MS (accessed: 24 January 2020).

16. Rabie A.I. Sodium gluconate as a new environmentally friendly iron-controlling agent for HP/HT acidizing treatments. SPE Middle East Oil \& Gas Show and Conference. 2015. Available at: http://dx.doi.org/10.2118/172640-MS (accessed: 24 January 2020).

17. Litvin V.T., Strizhnev K.V., Roshchin P.V. Features of the structure and intensification oil inflows in complex reservoirs of the Bazhenov formation of the Palyanovsky deposits. Oil and gas geology. Theory and practice, 2015, vol. 10, no. 3. In Rus. Available 
at: http://www.ngtp.ru/rub/11/36_2015.pdf (accessed: 24 January 2020).

18. Gilaev Gen.G., Khabibullin M.Ya., Gilaev G.G. Prospects for using acid gel for pumping proppant in the process of hydraulic fracturing of carbonate reservoirs in the Samara region. Oil industry, 2020, no. 8, pp. 54-57. In Rus.

19. Nsoga V.N., Hona J., Pemha E. Numerical simulation of heat distribution with temperature-dependent thermal conductivity in a two- dimensional liquid flow. International Journal of nonlinear sciences and numerical simulation, 2017, vol. 18, Iss. 6, pp. 507-513.

20. Abdyukova R.Y. Studies on operation and types of drilling pump valves. IOP Conference Series: Materials Science and Engineering. 2019. pp. 012050. DOI: 10.1088/1757-899X/560/1/012050

Received: 23 September 2020.

\section{Information about the authors}

Marat Ya. Khabibullin, Cand. Sc., associate professor, Branch of the Ufa State Petroleum Technical University in Oktyabrsky. 